\title{
Improving the production of transgenic fish germlines: In vivo evaluation of mosaicism in zebrafish (Danio rerio) using a green fluorescent protein (GFP) and growth hormone cDNA transgene co-injection strategy
}

\author{
Márcio de Azevedo Figueiredo, Carlos Frederico Ceccon Lanes, Daniela Volcan Almeida \\ and Luis Fernando Marins \\ Departamento de Ciências Fisiológicas, Fundação Universidade Federal do Rio Grande, Rio Grande, \\ RS, Brazil
}

\begin{abstract}
In fish, microinjection is the method most frequently used for gene transfer. However, due to delayed transgene integration this technique almost invariably produces mosaic individuals and if the gene is not integrated into germ cells its transmission to descendants is difficult or impossible. We evaluated the degree of in vivo mosaicism using a strategy where a reporter transgene is co-injected with a transgene of interest so that potential germline founders can be easily identified. Transgenic zebrafish (Danio rerio) were produced using two transgenes, both comprised of the carp $\beta$-actin promoter driving the expression of either the green fluorescent protein (GFP) reporter gene or the growth hormone cDNA from the marine silverside fish Odonthestes argentinensis. The methodology applied allowed a rapid identification of $G_{0}$ transgenic fish and also detected which fish were transmitting transgenes to the next generation. This strategy also allowed inferences to be made about genomic transgene integration events in the six lineages produced and allowed the identification of one lineage transmitting both transgenes linked on the same chromosome. These results represent a significant advance in the reduction of the effort invested in producing a stable genetically modified fish lineage.
\end{abstract}

Key words: transgenesis, genetically modified fish, microinjection, growth hormone cDNA.

Received: December 19, 2005; Accepted: July 6, 2006.

\section{Introduction}

Transgenesis involves genomic alteration of an organism through insertion, modification or deletion of a gene with the objective of modifying characteristics of interest (Houdebine, 2002; Carter, 2004). In this manner, new stable and genetically determined characteristics can be incorporated into the genome of the receptor organism and possibly transmitted to the next generations. In the last two decades, this technology has been successfully applied in fish due to the fact that these inferior vertebrates present reproductive and biological characteristics that allow easy manipulation of their genetic and physiological processes in the early stages of ontogenesis (Zhu and Shu, 2000). Studies of gene transfer have been carried out in more than 35 teleost species, most of which are important to aquaculture (Zbikowska, 2003). However, genetically modified fish have also been developed as experimental models for

Send correspondence to L.F. Marins. Departamento de Ciências Fisiológicas, Fundação Universidade Federal do Rio Grande, Av. Itália km 8, 96201-900 Rio Grande do Sul, RS, Brazil. E-mail: dqmluf@furg.br. biomedical research, especially in studies involving embryogenesis and organogenesis (Amacher, 1999; Motoike et al., 2000; Goldman et al., 2001; Huang et al., 2001; Takechi et al., 2003) as well as in the study of human diseases (Dodd et al., 2000; Dooley and Zon, 2000; Ward and Lieschke, 2002), xenotransplantation (Wright and Pohajdak, 2001; Leventhal et al., 2004; Pohajdak et al., 2004) and recombinant protein production for producing important therapeutic agents (Anderson and Krummen, 2002).

Several techniques are currently available for transgenic fish production which have been developed to increase the efficiency of transgene integration or to produce a large number of transformed individuals simultaneously. Although these new methods of gene transfer are gaining importance due to the encouraging results reported (Tanaka and Kinoshita, 2001; Lu et al., 2002; Grabher et al., 2003; Hostetler et al., 2003; Kinoshita et al., 2003; Kurita et al., 2004), microinjection in fish is still the most successful technique being used due to its simplicity and trustworthiness (Udvadia and Linney, 2003; Zbikowska, 2003). Maclean et al. (2002) stated that microinjection was the 
best technique to use with tilapia (Oreochromis niloticus). However, when microinjection is used to produce transgenic fish it almost invariably produces mosaic fish due to delayed transgene integration, which occurs only after a few cycles of embryonic cell division. If the transgene is integrated in only one cell group or tissue but not into germ cells the transmission of the gene to descendants is difficult or impossible (Maclean, 1998).

The use of reporter genes that allow evaluation of the degree of in vivo mosaicism in transgenic fish can facilitate identification of probable germline founders and the coinjection of a reporter transgene along with the gene construct of interest represents a considerable reduction in the effort needed for the establishment of transgenic germlines. The gene coding for the green fluorescent protein (GFP) from the jellyfish Aequorea victoria has been widely used as a reporter gene because it does not require an exogenous substrate for its activity (Amsterdam et al., 1995) and is stable and non-toxic in receptor organisms (Peters et al., 1995).

The objective of the work described in this paper was to develop an in vivo methodology to evaluate the degree of mosaicism and to identify transgenic zebrafish (Danio rerio) with the potential to generate germlines for the gene of interest.

\section{Material and Methods}

\section{Production of transgenic fish}

Adult wild-type zebrafish (Danio rerio) obtained from a commercial supplier were kept in a closed water circulation system at $28{ }^{\circ} \mathrm{C}$ under a $14 \mathrm{~h} \mathrm{light} / 10 \mathrm{~h}$ dark photoperiod. Freshly fertilized eggs were collected for microinjection and transgenic zebrafish produced using two transgenes containing the carp (Cyprinus carpio) $\beta$ actin promoter driving the expression of either the $A$. victoria GFP gene ( $\mathrm{pc} \beta \mathrm{A} / \mathrm{GFP}$ plasmid) or the marine silverside fish (Odonthestes argentinensis) growth hormone (msGH) cDNA ( $\mathrm{pc} \beta \mathrm{A} / \mathrm{msGH}$ plasmid). The pc $\beta \mathrm{A} / \mathrm{GFP}$ plasmid was kindly provided by Dr. Suzanne Brooks (University of Southampton, UK) and was used to produce the pc $\beta \mathrm{A} /$ msGH plasmid by replacing the GFP gene with the msGH cDNA (Marins et al., 2002). Both plasmids were linearized with the Spe I restriction enzyme and co-injected at a 1:1 molar ratio into one-cell embryos using a total DNA con-

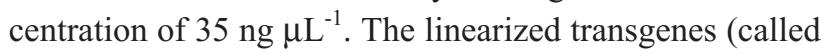
$\mathrm{c} \beta \mathrm{A} / \mathrm{GFP}$ and $\mathrm{c} \beta \mathrm{A} / \mathrm{msGH}$ ) were transferred in an equimolar ratio to provide the same integration and expression probability due to the fact that they had approximately the same length $(\mathrm{c} \beta \mathrm{A} / \mathrm{GFP}=5.6 \mathrm{~kb}$ and $\mathrm{c} \beta \mathrm{A} / \mathrm{msGH}=5.5 \mathrm{~kb})$ and were both under the action of the same promoter.

The microinjection process followed the general protocol recommended by Vielkind (1992) and used an IM-30 motorized picoinjector (Narishige, Japan) to inject approxi- mately $300 \mathrm{pL}$ of DNA solution representing a final number of $10^{6}$ copies of each transgene per injected embryo. The microinjection needles were produced from Narishige GDC-1 glass capillaries using the Narishige PC-10 micro-electrode puller. A total of 1872 one-cell embryos were injected. Non-injected controls and microinjected embryos were incubated at $28^{\circ} \mathrm{C}$ until hatching.

\section{Evaluation of mosaicism in the first transgenic generation $\left(G_{0}\right)$}

One week after fertilization the fish larvae were analyzed by epifluorescence microscope (excitation $=485 \mathrm{~nm}$; emission $=520 \mathrm{~nm}$ ) and classified according to their GFP expression patterns (Gibbs and Schmale, 2000; Thermes et al., 2002) as follows: weak = few cells expressing GFP; moderate $=$ less than $50 \%$ of the body expressing GFP; or strong $=$ more than $50 \%$ of the body expressing GFP.

\section{Evaluation of the msGH gene expression by RT-PCR}

To confirm $\mathrm{G}_{0}$ msGH gene expression we used the reverse transcriptase polymerase chain reaction (RT-PCR) to analyze several four-week old fish expressing GFP. Total RNA was extracted by humanely sacrificed $12 \mathrm{G}_{0}$ fish and homogenizing their bodies in TRIzol reagent (Invitrogen, Brazil) according to the protocol suggested by the manufacturer. Approximately $3 \mu \mathrm{g}$ of total RNA from each fish was used as template for the RT-PCR with the AP primer (5'-GGCCACGCGTCGACTAGTAC(T) $)_{17}$-3', Invitrogen, Brazil). The complementary DNA (cDNA) synthesis was carried out using the enzyme RT SuperScript III (Invitrogen, Brazil) according to the protocol suggested by the manufacturer. The cDNA obtained was used as template for the $\mathrm{msGH}$ gene amplification using the specific primers EXO 293 (5'-GAAAGCTCTCTGCAGACGGA G-3') and GHEX6-RIG (5'-AGAGTGCAGTTTGCCTCT GG-3'), which produce a $467 \mathrm{bp}$ msGH fragment but do not amplify the endogenous zebrafish growth hormone gene. PCR was carried out in a $12.5 \mu \mathrm{L}$ reaction volume containing $1.25 \mu \mathrm{L}$ of $10 \mathrm{X}$ PCR buffer, $0.2 \mu \mathrm{M}$ of each primer, $0.2 \mathrm{mM}$ of each dNTP, $0.75 \mathrm{mM}$ of $\mathrm{MgCl}_{2}, 0.5$ unit of Platinum Taq DNA polymerase (Invitrogen, Brazil) and $1 \mu \mathrm{L}$ of cDNA solution. The reaction was incubated at $94{ }^{\circ} \mathrm{C}$ for 2 min followed by 30 cycles of $15 \mathrm{~s}$ at $94{ }^{\circ} \mathrm{C}, 30 \mathrm{~s}$ at $65^{\circ} \mathrm{C}$ and $30 \mathrm{~s}$ at $72{ }^{\circ} \mathrm{C}$, and a final elongation step of $5 \mathrm{~min}$ at $72{ }^{\circ} \mathrm{C}$ and the PCR products separated on $1 \%(\mathrm{w} / \mathrm{v})$ agarose gel stained with ethidium bromide $(0.5 \mu \mathrm{g} / \mathrm{mL})$ and visualized by ultraviolet transillumination.

\section{Assessment of the biological effect of $\mathrm{msGH}$ in the $\mathrm{G}_{0}$ generation}

The objective of this experiment was to verify whether the msGH transgene produced significant biological effects in the growth performance of the transgenic indi- 
viduals. Groups of non-transgenic and $\mathrm{G}_{0}$ transgenic fish classified as strongly expressing GFP were reared until one-year old for comparison of their final average weight. Fish were fed ad libitum twice a day with a commercial fish food (ColorBits, Tetra) containing $47.5 \%$ protein. The average weight data were statistically analyzed using a t-test for heterogeneous variances contained in the Statistica program v. 6.0 (Statsoft, USA).

\section{Transmission of transgenes to the second $\left(G_{1}\right)$ and third $\left(G_{2}\right)$ transgenic generations}

A group of larvae showing strong GFP expression were selected and reared until sexual maturity as being probable germline founders. For the transgene transmission study, eight $\mathrm{G}_{0}$ mosaic fish classified as strong for GFP expression were separated in individual aquariums and crossed with non-transgenic fish. Two of these transgenic fish did not developed reproductive behavior. Six sexually mature transgenic fish were mated with wild-type fish to produce $\mathrm{G}_{1}$ offspring which were assessed by epifluorescence microscopy as described above to verify the presence of the uniform GFP expression expected after genomic integration. To confirm the presence of the $\mathrm{msGH}$ transgene in the $\mathrm{G}_{1}$ fish genome, GFP positive larvae were cultivated until adulthood and a small fin clip was taken from each fish and the genomic DNA extracted (Sambrook et al., 1989). The msGH gene was amplified using the specific primers EXO-293 and GHEX6-RIG and the PCR conditions described above. Only GFP positive $\mathrm{G}_{1}$ fish were tested for $\mathrm{msGH}$ because the objective was to identify $\mathrm{G}_{0}$ fish which were transmitting both transgenes to the descendants.

Twelve $G_{1}$ fish, six from each of two $G_{1}$ parents carrying both transgenes, were crossed with wild-type fish to produce $\mathrm{G}_{2}$ progeny, which were assessed using epifluorescence microscopy as described above. To verify whether or not the transgenes had integrated on the same chromosome, sub-samples of GFP positive and negative fish $(\mathrm{N}=12)$ were randomly selected from each lineage and their DNA extracted and subjected to PCR, using the conditions described above, to detect the presence of $\mathrm{msGH}$.

\section{Results}

Transgenic zebrafish were produced by the co-injection of 1872 one-cell embryos, using the transgenes $\mathrm{c} \beta \mathrm{A} / \mathrm{GFP}$ and $\mathrm{c} \beta \mathrm{A} / \mathrm{msGH}$ in an equimolar ratio (1:1). At the time of assessment by epifluorescence microscopy, one week after fertilization, the survival rate for untreated fish embryos was 1414 out of $1872(75.5 \%)$ while the survival rate of the microinjected embryos was 877 out of 1872 (46.8\%), of which 275 out of 877 (31.4\%) were classified as GFP negative (no expression), 315 out of 877 (35.9\%) as weakly GFP positive, 198 out of $877(22.6 \%)$ as moderately GFP positive and 89 out of $877(10.1 \%)$ as strongly
GFP positive. The sum of the three GFP expression classes was 602 out of 877 fish $(68.6 \%)$.

All of the 12 one-month old $\mathrm{G}_{0}$ GFP positive fish assessed for msGH expression by RT-PCR were msGH transgene positive. The analysis of the average weight after 12 months demonstrated a significant increase $(p<0.01)$ in the transgenic group $(1.79 \mathrm{~g} \pm 0.37)$ in relation to wild-type fish of the same age $(0.68 \mathrm{~g} \pm 0.13)$. This represents an increase in growth of 2.6 times for the transgenic group as compared with the non-transgenic fish, and shows the biological effect of expression of the $\mathrm{c} \beta \mathrm{A} / \mathrm{msGH}$ transgene in zebrafish (Figure 1).

In the transgene transmission study, eight $\mathrm{G}_{0}$ mosaic fish classified as strongly expressing GFP were crossed with non-transgenic fish. Two of the transgenic fish did not developed reproductive behavior but two males (M0104 and M0204) and four females (F0104, F0204, F0304 and F0404) reproduced, four of which (M0104, F0104, F0204 and F0304) transmitted the GFP gene to the $\mathrm{G}_{1}$ in percentages that varied from $2.2 \%$ to $42 \%$ (Table 1 ). The GFP expression pattern observed in the $\mathrm{G}_{1}$ offspring showed fish expressing the transferred gene in all body cells. However, the msGH gene was detected only in $\mathrm{G}_{1}$ descents obtained from the M0104 and F0104 parent fish. Only half the GFP-positive offspring of the M0104 parent were also carrying the msGH gene but for the F0104 parent all the GFP-positive offspring were also positive for the exoge-
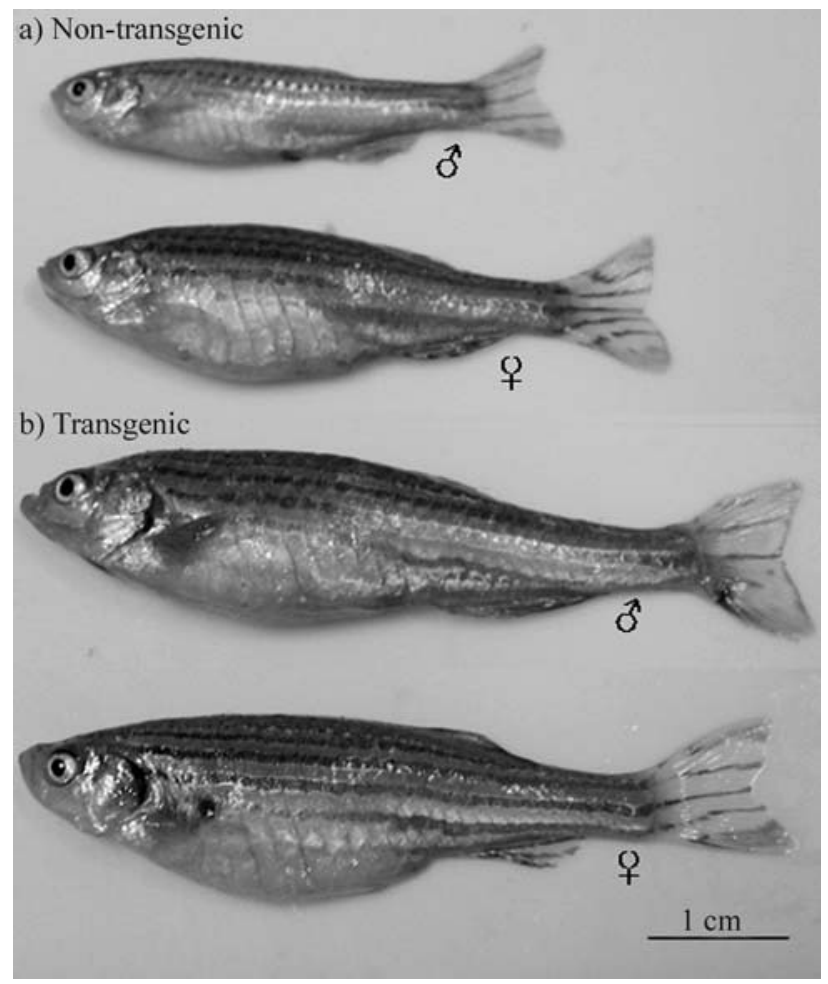

Figure 1 - Zebrafish (Danio rerio): (a) one-year old non-transgenic fish (average weight $=0.68 \pm 0.13$ ) and (b) one-year old $\mathrm{G}_{0}$ transgenic fish (average weight $=1.79 \mathrm{~g} \pm 0.37)$. 
Table 1 - Germline transmission and expression of a green florescent protein (GFP) reporter transgene (c $\beta A / G F P)$ and growth hormone transgene $(\mathrm{c} \beta \mathrm{A} / \mathrm{msGH})$ in transgenic zebrafish (Danio rerio).

\begin{tabular}{|c|c|c|c|c|c|c|}
\hline \multirow{2}{*}{$\begin{array}{l}\text { Transgenic lines } \\
\left(\mathrm{G}_{0}\right)^{*}\end{array}$} & \multirow{2}{*}{$\begin{array}{l}\text { Number of } \mathrm{G}_{1} \text { embryos } \\
\quad \text { expressing GFP } \\
\left(\% \text { transmission to } \mathrm{G}_{1}\right)\end{array}$} & \multirow{2}{*}{$\begin{array}{c}\mathrm{G}_{1} \mathrm{GFP}+\text { embryos carrying } \\
\text { the msGH gene } \\
(\%)\end{array}$} & \multicolumn{4}{|c|}{ Percentage of $\mathrm{c} \beta \mathrm{A} / \mathrm{GFP}$ and $\mathrm{c} \beta \mathrm{A} / \mathrm{msGH}$ segregation in $\mathrm{G}_{2}$ embryos $(\%$} \\
\hline & & & GFP+ & $\mathrm{GH}+$ & $\mathrm{GFP}+/ \mathrm{GH}+$ & GFP-/GH- \\
\hline M0104 & 50 out of $757(6.6)$ & 3.3 & 25 & 25 & 25 & 25 \\
\hline F0104 & 18 out of $812(2.2)$ & 2.2 & 0 & 0 & 50 & 50 \\
\hline F0204 & 119 out of $283(42)$ & 0 & - & - & - & - \\
\hline F0304 & 51 out of $167(30.5)$ & 0 & - & - & - & - \\
\hline M0204 & 0 out of $115(0)$ & - & - & - & - & - \\
\hline F0404 & 0 out of $107(0)$ & - & - & - & - & - \\
\hline
\end{tabular}

$* \mathrm{M}=$ male; $\mathrm{F}=$ female

nous GH gene (Table 1). No GFP gene expression was detected in the offspring of the M0204 and F0404 parents.

The $\mathrm{G}_{1}$ offspring of the M0104 and F0104 $\mathrm{G}_{0}$ mosaic parents which were positive for both transgenes were reared until sexual maturation and six $\mathrm{G}_{1}$ fish from each parent were mated with wild-type fish to produce $\mathrm{G}_{2}$ offspring. A total of $466 \mathrm{G}_{2}$ offspring resulted from the M0104 matings while $588 \mathrm{G}_{2}$ offspring were obtained from the F0104 matings. These results are summarized in Table 1 and indicate two different transmission patterns for each lineage. For the male M0104 parent the $\mathrm{G}_{2}$ offspring consisted of $25 \%$ negative for both transgenes, 25\% GFPpositive only, $25 \% \mathrm{msGH}$-positive only and $25 \% \mathrm{GFP} /$ msGH-positive, while for the female F0104 parent the $\mathrm{G}_{2}$ offspring consisted of $50 \%$ negative for both transgenes and positive for both transgenes.

\section{Discussion}

Although some methodologies have presented promising results in increasing first generation $\left(\mathrm{G}_{0}\right)$ transgenic fish production, there is still the problem of rearing large numbers of $\mathrm{G}_{0}$ fish and the subsequent identification of those with the potential to generate stable germlines carrying the active transgene. This process is even more difficult for large fish such as carp, salmon, tilapia or trout which need very complex culture facilities. The methodology applied in our study not only allowed the production of transgenic fish carrying the active transgene of interest $(\mathrm{c} \beta \mathrm{A} / \mathrm{msGH})$ but also the reporter transgene (c $\beta \mathrm{A} / \mathrm{GFP})$ which allowed the evaluation of mosaicism in all the $\mathrm{G}_{0}$ transgenic fish generated. The analysis of the GFP expression patterns permitted the selection of possible germline founders from the fairly low number of fish in the $\mathrm{G}_{0}$ generation.

A week after microinjection $68.6 \%$ of the fish embryos expressed GFP, which represents a high efficiency of transgenic fish production. However, part of this observed expression can be attributed to transitory expression due to the transcription of unintegrated transgenes (Chong and
Vielkind, 1989). Our results are significant when compared to the $1.95 \%$ transgenic zebrafish obtained by Morales et al. (2001) and the 10\% transgenic tilapia obtained by Rahman et al. (1997) using the same reporter transgene co-injection strategy. We found that $10 \%$ of the fish analyzed by us presented strong GFP reporter gene expression, significantly more than the 5\% with strong GFP expression reported by Gibbs and Schmale (2000) for $\mathrm{G}_{0}$ transgenic zebrafish and the $3 \%$ with strong GFP expression reported by Thermes et al. (2002) for $\mathrm{G}_{0}$ transgenic medaka. The conditions used by these authors were similar to ours and they also used linearized transgenes in which the GFP gene was controlled by ubiquitous promoters ( $\alpha$ and $\beta$-actin).

Although our RT-PCR analyses showed that $100 \%$ of the $\mathrm{G}_{0}$ GFP positive fish were expressing the $\mathrm{msGH}$ gene not all these fish were carrying the msGH transgene in their germ cells and could transmit the msGH transgene to the next generation, this being evident when the $G_{0}$ and wildtype fish were crossed. The growth experiment data supported our RT-PCR results and indicated that the transgenic group increased in weight 2.6 times more than the nontransgenic group. These results demonstrate that the $\mathrm{c} \beta \mathrm{A} / \mathrm{msGH}$ transgene was producing an active hormone. The higher weight of the transgenic fish was probably related to increased circulating $\mathrm{msGH}$ which could not be controlled by the negative feedback mechanism which regulates endogenous GH gene expression (Peter and Marchant, 1995).

The main negative consequence of mosaicism in transgenic fish germline production is the fact that the germ cells of $\mathrm{G}_{0}$ fish can receive few or no copies of the transgene, making transgene transmission to the next generation difficult or impossible (Maclean, 1998). However, this problem can be minimized by evaluating mosaicism using a reporter transgene co-injection strategy. This is supported in our study by the presence of strongly GFP-positive fish ( 2 out of 6 , or $33.3 \%$ ) transmitting both transgenes to the $G_{1}$ generation, indicating a considerable increase in the possibility of identification of germline founder fish. According to Maclean (1998), the rate of transgene transmission to the 
$\mathrm{G}_{1}$ is low, with only approximately $5 \%$ of $\mathrm{G}_{0}$ transgenic fish having the capacity to transmit transgenes to the next generation.

The percentage of GFP positive $\mathrm{G}_{1}$ fish produced in our study indicated the degree of mosaicism in the germ cells of the $\mathrm{G}_{0}$ fish. We found that two fish did not transmit any transgene to their descents, indicating that the transgenes were not integrated into the germ cells, while four fish transmitted the $\mathrm{c} \beta \mathrm{A} / \mathrm{GFP}$ transgene to produce $2.2 \%$ to $42 \%$ of GFP-positive descents. Therefore, despite the fact that some of our fish strongly expressed GFP, transgene integration into germ cells was extremely variable. In theory, if all the germ cells of a transgenic fish contained the transgene (i.e. no germ cell mosaicism) and this fish was mated with a wild-type fish $50 \%$ of the offspring would express the transgene. Maclean (1998) pointed out that generally only a small percentage of the offspring from $G_{1}$ mosaics are transgenic, which makes identification difficult when an easy detectable marker is absent. In our study, the identification of $G_{1}$ transgenic fish was greatly facilitated by the presence of the GFP gene reporter and simple evaluation using epifluorescence microscopy allowed rapid identification of the transgenic fish. Additionally, $\mathrm{G}_{1}$ fish originating from the F0104 female and the M0104 male (which were carrying both transgenes) were crossed with wild-type fish to verify how the transgenes integrated in the $\mathrm{G}_{2}$ fish genome. In the $\mathrm{G}_{2}$ produced from the M0104 lineage a number of GFP-positive fish did not carry the exogenous GH transgene while some GFP-negative fish were carrying it. This indicates that the $c \beta A / G F P$ and $c \beta \mathrm{A} / \mathrm{msGH}$ transgenes segregated in the $\mathrm{G}_{2}$, since the observed genotypic ratio (Table 1) is in accordance with genes situated on different chromosomes. However, for the F0104 lineage $\mathrm{G}_{2}$ descents all the GFP-positive individuals were carrying the $\mathrm{c} \beta \mathrm{A} / \mathrm{msGH}$ transgene as well as the $c \beta A / G F P$ transgene, indicating that both transgenes had been integrated on the same chromosome.

The methodology described in this paper allowed the rapid identification of $\mathrm{G}_{0}$ transgenic fish and also identified which fish were transmitting transgenes to the next generation. This strategy also allowed inferences to be made regarding genomic transgene integration events, and permitted the identification of the one lineage (out of the six produced) which contained and transmitted both transgenes linked on the same chromosome. These results represent a significant advance in the reduction of the effort involved in the production of genetically stable modified fish lineages.

\section{Acknowledgments}

This work was supported by the Brazilian agency Conselho Nacional de Desenvolvimento Científico e Tecnológico (CNPq-PROFIX, Proc. N. 540903/01-9) and Fundação Universidade Federal do Rio Grande (FURG).

\section{References}

Amacher SL (1999) Transcriptional regulation during zebrafish embryogenesis. Curr Opin Gen Dev 9:548-552.

Amsterdam A, Lin S and Hopkins N (1995) The Aequorea victoria green fluorescent protein can be used as a reporter in live zebrafish embryos. Dev Biol 171:123-129.

Anderson DC and Krummen L (2002) Recombinant protein expression for therapeutic applications. Curr Opin Biotechnol 13:117-123.

Carter L (2004) Re-interpreting some common objections to three transgenic applications: GM foods, xenotransplantation and germ line gene modification (GLGM). Transgenic Res 13:583-591.

Chong SSC and Vielkind JR (1989) Expression and fate CAT reporter gene microinjected into fertilized medaka (Oryzias latipes) eggs in the form of plasmid DNA, recombinant phage particles in its DNA. Theor Appl Genet 78:369-380.

Dodd A, Curtis PM, Williams LC and Love DA (2000) Zebrafish: Bridging the gap between development and disease. Hum Mol Genet 9:2443-2449.

Dooley K and Zon LI (2000) Zebrafish: A model system for the study of human disease. Curr Opin Genet Dev 10:252-256.

Gibbs PDL and Schmale MC (2000) GFP as a marker scorable throughout the life cycle of transgenic zebra fish. Mar Biotechnol 2:107-125.

Goldman D, Hankin M, Li Z, Dai X and Ding J (2001) Transgenic zebrafish for studying nervous system development and regeneration. Transgenic Res 10:21-33.

Grabher C, Henrich T, Sasado T, Arenz A, Wittbrodt J and Furutani-Seiki M (2003) Transposon-mediated enhancer trapping in medaka. Gene 322:57-66.

Hostetler HA, Peck SL and Muir WA (2003) High efficiency production of germ-line transgenic Japanese medaka (Oryzias latipes) by electroporation with direct current-shifted radio frequency pulses. Transgenic Res 12:413-424.

Houdebine LM (2002) La transgenèse et ses applications médicales. Pathol Biol 50:380-387.

Huang HG, Vogel SS, Liu NG, Melton DA and Lin S (2001) Analysis of pancreatic development in living transgenic zebrafish embryos. Mol Cell Endocrinol 177:117-124.

Kinoshita M, Yamauchi M, Sasanuma M, Ishikawa Y, Osada T, Inoue K, Wakamatsu Y and Ozato K (2003) A transgene and its expression profile are stably transmitted to offspring in transgenic medaka generated by the particle gun method. Zoolog Sci 20:869-875.

Kurita K, Burgess SM and Sakai N (2004) Transgenic zebrafish produced by retroviral infection of in vitro-cultured sperm. Proc Natl Acad Sci USA 101:1263-1267.

Leventhal JR, Sun J, Zhang J, Galili U, Chong A, Baker M, Kaufman DB and Wright Jr JR (2004) Evidence that tilapia islets do not express alpha-(1,3)gal: Implications for islet xenotransplantation. Xenotransplantation 11:276-283.

$\mathrm{Lu}$ JK, Fu BH, Wu JL and Chen TT (2002) Production of transgenic silver sea bream (Sparus sarba) by different gene transfer methods. Mar Biotechnol 4:328-337.

Maclean N (1998) Regulation and exploitation of transgenes in fish. Mutat Res 399:255-266.

Maclean N, Rahman MA, Sohm F, Hwang G, Iyengar A, Ayad H and Smith A (2002) Transgenic tilapia and the tilapia genome. Gene 295:265-277. 
Marins LF, Iyengar A, Maclean N, Levy JA and Sohm F (2002) Simultaneous overexpression of GH and STAT5b genes inhibits the STAT5 signalling pathway in tilapia (Oreochromis niloticus) embryos. Genet Mol Biol 23:293298.

Morales R, Herrera MT, Arenal A, Cruz A, Hernández O, Pimentel R, Guillén I, Martínez R and Estrada MP (2001) Tilapia chromosomal growth hormone gene expression accelerates growth in transgenic zebrafish (Danio rerio). Electron J Biotechnol 14:1-7.

Motoike T, Loughna S, Perens E, Roman BL, Liao W, Chau TC, Richardson CD, Kawate T, Kuno J, Weinstein BM, Stainier DYR and Sato TN (2000) Universal GFP reporter for the study of vascular development. Genesis 28:75-81.

Peter RE and Marchant TA (1995) The endocrinology of growth in carp and related species. Aquaculture 129:299-321.

Peters KG, Rao PS, Bell BS and Kindman LA (1995) Green fluorescent fusion proteins: Powerful tools for monitoring protein expression in live zebrafish embryos. Dev Biol 171:252-257.

Pohajdak B, Mansour M, Hrytsenko O, Conlon JM, Dymond LC and Wright Jr JR (2004) Production of transgenic tilapia with Brockmann bodies secreting [desThrB30] human insulin. Transgenic Res 13:313-323.

Rahman MA, Iyengar A and Maclean N (1997) Co-injection strategy improves integration efficiency of a growth hormone gene construct, resulting in lines of transgenic tilapia (Oreochromis niloticus) expressing an exogenous growth hormone gene. Transgenic Res 6:369-378.
Sambrook J, Fritsch EF and Maniatis T (1989) Molecular Cloning: A Laboratory Manual. 2nd edition. Cold Spring Harbor Laboratory Press, Cold Spring Harbor, New York.

Takechi M, Hamaoka T and Kawamura S (2003) Fluorescence visualization of ultraviolet-sensitive cone photoreceptor development in living zebrafish. Febs Letters 553:90-94.

Tanaka M and Kinoshita M (2001). Recent progress in the generation of transgenic medaka (Oryzias latipes). Zoolog Sci 18:615-622.

Thermes V, Grabher C, Ristoratore F, Bourrat F, Choulika A, Wittbrodt J and Joly JS (2002) I-SceI meganuclease mediates highly efficient transgenesis in fish. Mech Dev 118:9198.

Udvadia AJ and Linney E (2003) Windows into development: Historic, current, and future perspectives on transgenic zebrafish. Dev Biol 256:1-17.

Vielkind JR (1992) Medaka and zebrafish: Ideal as transient and stable transgenic systems. In: Hew CL and Fletcher GL (eds) Transgenic Fish. World Scientific, Singapore, pp 72-91.

Ward AC and Lieschke GJ (2002) The zebrafish as a model system for human disease. Front Biosci 7:D827-D833.

Wright JR and Pohajdak B (2001) Cell therapy for diabetes using piscine islet tissue. Cell Transplant 10:125-143.

Zbikowska HM (2003) Fish can be first - Advances in fish transgenesis for commercial applications. Transgenic Res 12:379-389.

Zhu ZY and Shu YH (2000) Embryonic and genetic manipulation in fish. Cell Res 10:17-27.

Associate Editor: Luiz Lehmann Coutinho 